\title{
O Brasil na América Latina na concepção de Manoel Bomfim'
}

Cristiane da Silveira ${ }^{2}$

Universidade do Estado do Amazonas- Brasil

Artículo de reflexión derivado de investigación

Recibido: agosto 17 de 2012 - Aprobado: octubre 19 de 2012

\section{Resumo:}

O presente artigo investiga as narrativas de Bomfim e sua concepção sobre o Brasil na América Latina a partir da análise da obra América Latina: Males de origem e permite refletir sobre alguns aspectos dos discursos na virada do século XIX para o XX, visto que a perspectiva de análise de Bomfim intentou romper com estigmas relativos ao Brasil e à América Latina no que diz respeito ao desenvolvimento econômico e social.

Palavras-chave: Manoel Bomfim; História; interpretação historiográfica; pensamento social brasileiro; progresso socioeconômico; Brasil; América Latina; Investigação.

\section{Brasil en América Latina en la concepción de Manoel Bomfim}

\section{Resumen:}

Este artículo investiga las narrativas de Manoel Bomfim y su concepción sobre el Brasil y la América Latina a partir del análisis de la obra América Latina: Males de origen, y permite reflexionar sobre algunos aspectos de los discursos en la transición del siglo XIX para el $X X$, considerando que la perspectiva de análisis de Bomfim intentó romper con estigmas sobre el Brasil y América Latina en lo que concierne al desarrollo económico y social.

Palabras-clave: Manoel Bomfim; Historia; interpretación historiográfica; pensamiento social brasileño; progreso socio-económico; Brasil; América Latina; Investigación.

I Este artigo é fruto do projeto de pesquisa (Re)leituras de Manoel Bonfim: a escrita da história do Brasil e o ser negro na passagem do século XIX para o XX, que foi financiado pela CAPES - Coordenação de Aperfeiçoamento de Pessoal de Ensino Superior - e resultou na Tese de Doutorado aprovada em 201 I no Programa de Pós-Graduação em História Social da Pontifícia Universidade Católica de São Paulo.

2 Doutora em História e professora da Universidade do Estado do Amazonas (UEA/CEST).

E-mail: silcristiane@yahoo.com.br 


\title{
Brasil in Latin America According to Manoel Bomfim
}

\begin{abstract}
:
This article researches Manoel Bomfim's narratives and his conception of Brasil and Latin America based on the study of América Latina: Males de Origem, and allows us to reflect on some aspects of discourses regarding the transition from the XIXth centuty to the $X X$ th, taking into consideration that Bomfim tried to finish with the stigma of Brasil and Latin America's economic and social development.
\end{abstract}

Keywords: Manoel Bomfim; history; historical interpretation; Brazilian social thought; social-economic development; Brazil; Latin America; research.

\section{Introdução}

Em suas primeiras décadas republicanas a história do Brasil foi pensada a partir das várias tramas que compuseram sua escrita, sua imagem e sua identidade. Neste artigo investigo as narrativas que Manoel Bomfim construiu sobre a história do Brasil e interações com a América Latina. Sublinho que o referido autor foi um dos primeiros pensadores brasileiros a buscar essa perspectiva de análise. A sua obra destoou da intelectualidade de sua época e trilhou caminhos para a análise dos fenômenos sociais, pautada na sua paixão pelo país, no reconhecimento da igualdade na diferença - isso no que dizia respeito às várias etnias presentes no contexto brasileiro - e na reflexão sobre o progresso social que se contrapunha ao progresso capitalista. Enfim, buscou construir outra história do Brasil, que não nos moldes do positivismo ${ }^{3}$ que imperava em seu tempo.

Manoel Bomfim (I 868-1932) era sergipano, médico, historiador, educador, um homem político, que escreveu vasta obra ${ }^{4}$ abrangendo vários campos do conhecimento, quando estes ainda não estavam configurados tal como nos dias atuais, entre eles a história, a psicologia, a medicina e a educação. Apesar de sua obra apresentar-se como significativa no conjunto do pensamento social brasileiro, foi relegada por algumas décadas em meio ao silêncio, o que não significou dizer que tenha

3 pensamento positivista dominou o panorama intelectual brasileiro no período da constituição da história enquanto campo da ciência, na virada do século XIX para o XX, tendo como referência autores como Augusto Comte. A esse respeito ver, por exemplo: LINS, Ivan. História do positivismo no Brasil. São Paulo: Companhia Editorial Nacional, 1967.

4 Obras de Bomfim: Pensar e dizer: estudo do símbolo no pensamento e na linguagem. Rio de Janeiro: Casa Electrus, 1923 ; O Brasil na História: deturpações das tradições, degradação política. Rio de Janeiro: Pongentti, I932; América Latina: males de origem. Rio de Janeiro: Topbooks, 1993; O Brasil Nação: realidade da soberania nacional. Rio de Janeiro: Topbooks, 1996. O Brasil na América: caracterização da formação brasileira. Rio de Janeiro: Topbooks, 1997; Através do Brasil: prática da língua portuguesa. Organização Marisa Lajolo. São Paulo: Companhia das Letras, 2000; Cultura e Educação do povo brasileiro. Rio de Janeiro: Pongentti. Deve-se lembrar que o autor também produziu na área de psicologia e educação e publicou artigos de variados temas para periódicos e jornais. 
sido completamente banida do meio intelectual. Mesmo tendo certo prestígio social ${ }^{5}$ em seu tempo, Bomfim não obteve de seus contemporâneos, efetivamente, o reconhecimento da importância de suas análises. Assim, recorre-se à imagem do "radical", construída por Antonio Candido 6 , o intelectual que se opôs ao pensamento conservador elitista e que, no entanto, não conseguiu (ou não intentou) romper totalmente com sua classe, mas foi fruto da transição entre o velho e o novo na formação do pensamento social brasileiro.

Em seu tempo Bomfim refletiu sobre a realidade brasileira. No conjunto de sua produção intelectual formulou por meio da escrita - livro de leitura e ensaios históricos - interpretações singulares sobre o Brasil, sua identidade e a formação das camadas sociais que o compõem, numa perspectiva de conflito multirracial, muitas vezes negada pelo discurso hegemônico, ou seja, pelos grupos que dominavam o cenário político e econômico, pautados em noções de civilidade, de branqueamento da população e de progresso econômico.

Para se compreender sua fala como contra-discurso tomaremos em conta a perspectiva da pesquisadora Regma Maria dos Santos ${ }^{7}$ que, ao trabalhar as crônicas de Lycídio Paes, um jornalista do interior do Brasil, trouxe importante contribuição para o entendimento sobre a relação escritorl contexto histórico/pensamento hegemônico e o seu contrário. Ao estabelecer, como propósito de pesquisa, "revelar que, por trás de um discurso aparentemente hegemônico, outros elementos se apresentam tornando mais dinâmico e dialético o pensamento de Lycídio Paes", a autora chama a atenção para as reflexões que, mesmo nascendo às avessas do pensamento hegemônico, estão inseridas em um momento determinado. Há, de acordo com Santos, um constante diálogo entre o pensamento hegemônico e os discursos construídos à sua margem, o que os coloca em ponto estratégico para análise da sociedade na qual estão inseridos.

Se na vida privada Bomfim era um sujeito que pouco se mostrava, é na escrita que revelou seus sentimentos mais íntimos sobre o amor ao Brasil que o envolveram ao escrever América Latina: Males de Origem. Essa obra começou a ser rascunhada em março de 1903, quando o pensador se encontrava na França, sentindo-se instigado a responder à "reputação perversamente malévola de que a América do Sul é vítima", ou seja, sua intenção primeira foi refutar o preconceito existente na visão do europeu sobre o Brasil, desenhando-lhe novas imagens, fugindo das armadilhas impostas pela modernidade europeia.

Os fios que construíram a imagem do Brasil e do ser brasileiro em seus escritos conduzem à reflexão sobre as idéias de latinidade, a crítica aos ideais de progresso econômico X progresso social,

5 Bomfim contribuiu para a organização da Academia Brasileira de Letras, mas não figurou entre os intelectuais consagrados do período; desempenhou importante papel na administração pública, no âmbito da educação no Rio de Janeiro; frequentava rodas de intelectuais e foi deputado federal pelo estado de Sergipe.

6 CÂNDIDO, Antonio. Radicalismos. In: Revista do Instituto de Estudos Avançados. São Paulo, v.4 (8): 4- I8, janeiro/abril, 1990.

7 SANTOS, Regma Maria dos. Memórias de um plumitivo: Impressões cotidianas e histórias nas crônicas de Lycidio Paes. Uberlândia: Asppectus, 2005, pág. 35.

8 lbidem, pág. 25. 
e a formação da identidade em uma perspectiva dinâmica. A obra de Bomfim possibilita compreender o ser negro, rompendo com a imagem depreciativa vigente naquele momento. $O$ pensador, ao longo de suas narrativas, em América Latina: Males de Origem crítica a suposta inferioridade racial presente na América Latina e no Brasil. Naquele momento, a invenção da América Latina e a inferioridade racial estavam entrelaçadas.

\section{Bomfim e seus fios de latinidade e de progresso}

Nos escritos de Bomfim, tem-se o caminho para a (des)construção das imagens negativas sobre a América Latina e os americanos. América Latina, denominação forjada no processo de formação do Estado-Nação dos países colonizados, ou seja, uma "invenção", entre tantas outras do período analisado, em discurso e não em realidade. Estigmas da inferioridade: agitadores, mundo lendário, riquezas à espera de "descobrimento", imagens de latinidade que se entrecruzam e denominam realidades múltiplas, muitas vezes contadas em uma narrativa homogênea, silenciando histórias e sujeitos, cristalizando a idéia do latino como ser não civilizado, longe dos ideais do progresso econômico alardeados pelos países colonizadores. Em um primeiro momento, Bomfim instiga o olhar sobre a América Latina e o latino, a partir do que foi construído pelo europeu:

A opinião publica européia sabe que existe a América Latina ... e sabe mais: que é um pedaço de continente muito extenso, povoado por gentes espanholas, continente riquíssimo, e cujas populações revoltam-se freqüentemente. Essas coisas porém, já Ihe aparecem um vago mal limitado: riqueza, terras vastas, revoluções e povos, tudo se confunde para formar um mundo lendário, de lendas sem grande encanto porque lhes falta o prestígio da ancianidade. Onde estão essas riquezas, o que valem; como se fazem as revoluções, quem as faz, onde as fazem: são questões que não se definem, sequer no obscuro longínquo desta visão única - A América do Sul ... É dela que se falam. Mesmo quando venham nomes particularizados - Peru, Venezuela, Uruguai ... não se importa; o que está ali, a imagem que se tem na mente é da América do Sul. ${ }^{9}$

Nas imagens da América construídas pelo olhar europeu, chamava a atenção uma suposta unidade que, na perspectiva de Bomfim, nunca existiu. Ele ressalta outro aspecto negativo, visto pelos europeus na América, sua falta de "ancianidade". Essa concepção estava interligada a elementos de civilidade, na unificação dos gestos/cultura e do progresso econômico, ou seja, uma tradição polítical econômica que não existia na América Latina, um continente "novo", mas encontrava-se fortemente presente na Europa. "Ancianidade" que determinava na Europa as tradições de cada país, a história construída ao longo dos anos. Bomfim acredita no fazer-se das tradições do Brasil, que culminaria no

9 BOMFIM, Manoel. América Latina: Males de Origem. 4a. Ed. Rio de Janeiro: Topbooks, 1993, págs. 37-38 (citação da publicação original e assim doravante). 
processo de afirmação de sua história e de sua identidade, linhas que seriam traçadas potencializando-se a diversidade étnica do país, a ideia do herói que lutou pela independência do Brasil e a contribuição das várias etnias na formação do caráter brasileiro.

A partir da realidade vivida, o autor entendia a América Latina apenas como um aglomerado de países reunidos sob um mesmo nome. No entanto, sem nenhum traço comum unindo efetivamente as nações. Não eram, então, irmãs em espírito:

Nós outros - Argentinos, Peruanos, Brazileiros, Chilenos... que somos dos chamados latino-americanos, nunca pensamos em América Latina. Para nossos conceitos de realidade, no simples positivo das relações communs, ou como convergência de qualquer acção immediata, tal unidade não existe. Consideramos, apenas, cada um dos povos com que os dissertadores formavam o latinismo da América. $\bigcirc$ mesmo acontece a qualquer estrangeiro que feito vida conosco: falará de Venezuela, Paraguay, México, Nicarágua ... mas nunca sentirá a necessidade de concentrar o espírito, nesse concepto de América Latina. Em compensação todos que não nos conhecem, si fazedores de theorias, com a lingua em cousas social, históricas ou políticas, não falham no repetir de emphaticos e pueris preconceitos a cerca da inicial unidade da América Latina. ${ }^{10}$

De acordo com Bomfim, ao longo do tempo, essa unidade se fez, mas apenas como instrumento de re-afirmação da negatividade da noção de latinidade e da inferioridade racial presentes, seja na figura do indígena, do negro ou da mistura entre as raças. A multiplicidade racial em solo americano, no imaginário europeu, agiu como elemento fortalecedor do preconceito contra os latinos e determinava/legitimava a superioridade europeia. $\bigcirc$ pensador descreveu o conhecimento dos europeus sobre a América e evidenciou narrativas totalizantes: riqueza, grandes extensões de terras e lendas. Estas imagens, por um lado, demonstravam conhecimento sobre a existência da América na perspectiva europeia, largamente difundida pelos viajantes que por aqui passaram, mas por outro lado, evidenciava o desconhecimento acerca das singularidades das tramas históricas vividas na América, transformando-a num todo homogêneo e vazio. Passado mais de um século, essas imagens totalizantes sobre a América Latina ainda persistem. Para Maria Ligia Prado:

tratamento que se tem dado à história geral dos países da América Latina nos revela duas posições problemáticas. A primeira é a de assumir uma perspectiva homogeneizante, que pretende englobar todos os "casos" ao modelo estabelecido. A segunda, oposta, mas não melhor, é a da simples enumeração dos "casos", já que se considera incorreto ou inadequado o viés globalizante."

I0 Ibidem, pág. II.

II PRADO, Maria Lígia. A formação das nações latino-americanas. São Paulo: Atual, 1994, pág. 4. 
Para Bomfim a força do discurso europeu sobre a diversidade étnica cristalizou a inferioridade no olhar do latino sobre si próprio:

O lastimável, em tudo isto, é que nós mesmos - chilenos, mexicanos ou brazileiros... de tanto encontrar o conceito, na nitidez e simplicidade dos termos acabaremos adimittindo que deve existir uma América Latina, no sentido dos que, com esse epitheto, nos condemmam, isto é, chegaremos a pensar - que soffremos de inferioridade essencial, um qual peccado original ethnico, e que nos faz irremissivelmente degradados, todos num mesmo destino. Ora devemos reagir contra taes e effeitos, reagir, sobretudo em nós mesmos, comprhendendo bem toda a extensão dos defeitos de que realmente sofremos, analysando-os objectivamente, buscando-lhes cuidadosamente as origens que são, com as tradições coloniais dos povos metropoles, as condições mesma da formação nacional. ${ }^{12}$

Estaria, aí, para Bomfim, a "invenção" da América, pois de "tanto encontrar o conceito, na nitidez e simplicidade dos termos acabaremos admitindo que deve existir uma América Latina", invenção que vem do estrangeiro e condena o presente latino ao subdesenvolvimento, ao olhar negativo sobre si. Invenção que, para o autor, definia os caminhos trilhados pelos países integrantes do continente latino-americano, atrelado às relações estabelecidas entre o país colonizador e a colônia e, posteriormente, entre as classes dominantes e dominadas, termos utilizados por Bomfim. A origem brasileira encontrava-se na colonização, na tradição de exploração da metrópole, em contraponto às realidades vividas na América, no processo de formação nacional. $\bigcirc$ passado determinava o presente e estava entrelaçado à questão étnica, pois a inferioridade se fazia, principalmente, a partir da diversidade étnica. No olhar de Bomfim, muito do atraso econômico vivido pelo latino vinha deste estigma negativo criado pelo europeu:

Depois que um estrangeiro qualquer, ignorante das condições sociais do homem do povo na América do Sul, o denunciou como preguiçoso e incapaz de trabalhar, o pobre americano não achou mais salvação. Pouco importam todas as qualidades de resistência e sobriedade que ele possui; pouco importa que the falte apenas, a educação do trabalho e a instrução; foi condenado, e todos repetem a condenação, sem um instante de reflexão, sem atenuantes. É a sentença implacável, acompanhada com os panegíricos clássicos ao trabalhador estrangeiro - muitos e longos elogios das miraculosas virtudes da emigração. ${ }^{13}$

"Estrangeiro ignorante" foi o termo utilizado pelo autor para explicar a "cegueira" do olhar estrangeiro, responsável pela imagem negativa sobre o latino-americano e, conseqüentemente, sobre seu atraso, que alicerçou as ações presentes, condenando o latino a uma "sentença implacável", sem

12 BOMFIM, Op. cit., pág. 16.

13 Ibidem, págs. 176-177. 
condições de potencializar as singularidades nacionais. A latinidade vivida, a partir da "condenação" e da "sentença implacável" se configurou em argumentos fortes, imagem firmada a partir do olhar do outro, do europeu, que não buscou as singularidades e as lutas presentes em solo americano. Ou então, se o fez, foi como meio de reafirmar a negatividade, a barbárie em que viviam os latinos.

Se em um primeiro olhar, identifica-se imagens comuns sobre a América, nos seus escritos o autor segue chamando atenção para a necessidade de trazer à tona as particularidades, das quais, cada país latino era composto. Para Bomfim, a diversidade étnica presente no Brasil o fez um país diferente, mas não inferior. Neste ponto, rompe com as teorias raciais europeias e, conseqüentemente, com o pensamento hegemônico ao seu redor, uma vez que a inferioridade racial sedimentava os discursos dos intelectuais brasileiros, entre eles Silvio Romero, Nina Rodrigues e outros. Assim, Bomfim caracteriza a questão racial na América Latina:

Na constituição orgânica dos povos sul-americanos, entra uma grande dose de sangue indiano, e, em algumas das novas nacionalidades - Cuba, Brasil... - entra, também, um forte contingente de elementos africanos. Se, de fato, estas duas raças são inferiores, que dizer incapazes de alcançar o grau de perfeição que ora apresentam os vários povos europeus, é lógico que as nacionalidades da América Latina participarão dessa inferioridade. Já vimos que a teoria em si, não vale grande coisa, todavia, há uma tal unanimidade nos sociólogos a serviço dos fortes em chamar de "inferiores" a estas raças, que é mister discutir miudamente as suas apreciações. Os argumentos de que servem os tais sociólogos são: I) que os indígenas têm sido exterminados - eliminados - pelos brancos, o que prova serem eles inferiores; 2) que estes povos, são, geralmente, muitíssimo mais atrasados que os brancos; são todos selvagens ou bárbaros, e este atraso geral tem como causa, certamente, uma inferioridade étnica essencial.

Como o apoio ao primeiro dos argumentos invoca-se a teoria evolucionista de Darwin - a luta pela vida e a sobrevivência dos mais aptos. ${ }^{14}$

Bomfim, tal como outros autores do seu tempo, não negou a mistura entre as raças na formação étnica brasileira. No entanto, para escritores como Silvio Romero e Euclides da Cunha, as contribuições dos indígenas e dos negros para a formação brasileira eram enfatizadas no sentido de reafirmar a inferioridade apontada pelos europeus. ${ }^{15}$ Para o autor, esse argumento tinha intenções que

14 Ibidem, pág. 248.

I5 A ideologia darwinista "é introduzida no ambiente brasileiro através, sobretudo, das idéias de Gobineau, Lapouge e Le Bon. Este último autor, um dos escritores mais vendidos nas livrarias do Rio de Janeiro até os anos 1920, afirmava que os países de raça mestiça, entre os quais o Brasil, com um terço de brancos e a maioria negros e mulatos, estavam condenados ao fracasso". SILVA, José Maria de Oliveira. "Manoel Bomfim e a obra América Latina: a dialética entre passado e presente" in Manoel Bomfim e a América Latina: a dialética entre o passado e o presente. CRUZ, José Vieira da; JÚNIOR, Antonio Bittencourt (org.). Aracajú: Editora Diário Oficial, 20I0, pág. 50. 
estavam além da mera questão científica, ou seja, a de justificativa da dominação ${ }^{16}$ e de exploração de uma classe sobre outra. Para ele a teoria de Darwin, largamente utilizada, por si só, não justificava as análises dela decorrentes:

Quão diferentes são estas idéias daquelas que Oliveira Martins pretende existir na filosofia do grande naturalista!... Certamente o escritor lusitano nunca leu as cartas de Darwin, escritas depois de ter morado no Brasil, e de conhecer, por si mesmo, uns e outros: o negro, inferiorizado pela pirataria evolucionista, e os que o cativaram, e cuja superioridade bem se exprime pela grandeza da invenção - o tráfico dos africanos... Devia ter lido, para ver o horror e a indignação humanitária com que ele se refere à abjeção e iniqüidade desses homens, que, em nome de uma superioridade, cometem sobre criaturas humanas tais crimes. ${ }^{17}$

pensador coloca-se em diálogo com Oliveira Martins e Darwin para construir sua crítica à questão da inferioridade dos negros e, conseqüentemente, à da escravidão. Segundo Bomfim, houve deturpação das palavras de Darwin. Em nota de rodapé, recorrendo às correspondências de Darwin, procurou demonstrar, a partir das palavras do cientista, o fundamento da sua hipótese: "Conheço, agora, bastante a escravidão e o caráter dos negros, para estar sobejamente enjoado das mentiras e das asneiras que a esse respeito se ouvem na Inglaterra." 18

\section{Progresso social, progresso econômico e inferioridade racial no Brasil e na América Latina}

Bomfim jogou com as palavras "perfeição", "inferioridade" e "raça" para demonstrar que a sociedade e seus "homens" não estavam fadados à estagnação e à inferioridade. Para ele, essa justificativa se deu, principalmente, a partir de duas explicações centrais: o extermínio dos indígenas, por conta da sua inferioridade, e o fato de que esses povos eram bárbaros. Indica o quanto, a seu ver, as sociedades ameríndias encontravam-se avançadas antes da chegada dos europeus:

Ao desembarcarem na América, os espanhóis encontraram aí dois impérios, cujo estado de civilização era superior ao da Europa central no século IV, ou no V. Esta civilização era a obra exclusiva das raças indígenas, e ela nos diz, sem contestação possível, que, se estes povos puderam sair da selvageria primitiva e alcançar o grau de organização social em que estavam, poderiam muito bem avançar até

16 Pensador analisa a realidade a partir dos sentimentos, da paixão; às vezes, enveredando-se pela denúncia contra a realidade opressora a que alguns estavam sujeitos com a aceitação das teorias de superioridade racial: "Que vem a ser esta teoria? Como nasceu ela? A resposta a estas questões nos dirá que tal teoria não passa de um sofisma abjeto do egoísmo humano, hipocritamente mascarado de ciência barata, e covardemente aplicado à exploração dos fracos pelos fortes." BOMFIM, op. cit., pág. 243.

17 Ibidem, pág. 246.

18 Ibidem, pág. 25।. 
chegar ao mesmo estado de civilização e cultura de que se orgulham os europeus. $^{19}$

Ao defender suas ideias sobre a inexistência da inferioridade inata, Bomfim argumentou que os povos ameríndios alcançaram estágios de evolução que se equiparavam aos moldes europeus e que, no entanto, não foram "entendidos/vistos" pelos europeus. A igualdade, no olhar destes, se faria apenas entre os "iguais", o "outro" seria o inferior. Assim, centrou sua argumentação no sentido de demonstrar a capacidade dos "povos primitivos" para o progresso, como qualquer povo ariano. No entanto, os discursos da inferioridade racial eram violentos e terminaram por legitimar relações de franca hostilidade racial20, sendo que os argumentos colocados abriram perspectivas, naquele momento, para se entender a inferioridade e o progresso por meio de outro olhar.

Acusam-nos, ainda de indolentes, indisciplinados, imprevidentes, preguiçosos, defeitos que não são exclusivos dos mestiços, e pertencem ao geral das nações latinas da América. São defeitos mais de educação, devidos à ignorância em que vivem, ao abandono a que as condenam. Não trabalham porque não sabem trabalhar, não conhecem o valor do trabalho. ${ }^{21}$

Neste sentido, para além da formação plural, o pensador instiga à reflexão sobre a relação entre o progresso e a questão étnica, que era discurso corrente naquele período. Progresso que significa "um conjunto de mudanças havidas no curso do tempo, marcha para a frente" não foi algo que no Brasil trouxesse apenas fatos positivos. Trouxe também prejuízos para o índio, o negro, o mestiço e o pobre branco. O progresso não chegou na mesma dimensão de inovação conhecido pelas classes dominantes. Assim, a virada do século XIX para o XX foi um momento de crise pois, no Brasil, as elites desejavam implantar o novo que pretendia enterrar o antigo, mas este ainda não havia sido superado no cotidiano de muitos brasileiros oprimidos pelas péssimas condições de vida.

Vale lembrar que os ideais de progresso e de modernidade foram introduzidos no Brasil em realidades política, econômica e social muito distantes das europeias, tornando-se aqui uma experiência peculiar. Como enfatiza Weber: "fora da Europa nem o desenvolvimento científico, nem o artístico, nem o político, nem o econômico seguem a mesma via de racionalidade que é própria do Ocidente."'22 A modernidade que se fez na Europa foi única, já em outros locais as experiências vivenciadas, designadas como modernidade, foram eventos diferenciados. Modernidade e progresso foram ideais introduzidos pelo discurso hegemônico, como instrumento para padronizar as várias

19 Ibidem, págs. 252-253.

20 AGUIAR, Ronaldo Conde. Manoel Bomfim: um intérprete dissonante dos Males da America Latina. In: Manoel Bomfim e a América Latina: a dialética entre o passado e o presente. CRUZ, José Vieira da; JÚNIOR, Antonio Bittencourt (org.). Aracajú: Editora Diário Oficial, 2010 , pág. 216.

21 BOMFIM, op. cit., pág. 265.

22 Apud BERMAM, Marshall. Tudo que é sólido se desmancha no ar: A aventura da modernidade. São Paulo: Companhia das Letras, 1986, pág. 3. 
realidades vividas no Brasil. No entanto, o que se identifica são atos de violência, que buscaram impor a submissão da população negra e indígena e que legitimaram a desigualdade entre as etnias presentes em solo brasileiro.

Na virada do século XIX para o $X X$, era recorrente a ideia do progresso como superação do presente vivido, o destino natural de cada nação/sociedade. Os negros e indígenas eram considerados inferiores, por não pactuarem com o "viver o progresso", conforme a visão hegemônica. A noção de progresso amplamente divulgada e aceita estava ligada, principalmente, ao âmbito econômico.

Em seu tempo, Bomfim construiu caminhos para o entendimento do progresso e dos diferentes estágios em que os povos se encontravam e que instiga à reflexão sobre o progresso e sua ligação com as questões étnicas presente no Brasil. O progresso foi caracterizado, nos argumentos do autor, a partir de duas conotações distintas: o progresso econômico e o progresso social. Assim,

É a riqueza, o progresso industrial e comercial principalmente, que impressiona os sociólogos e políticos que nos condenam; este progresso prova efetivamente uma grande energia e tenacidade por parte dos norte-americanos, prova o espírito empreendedor de que eles são dotados. Não refletem, porém, tais políticos e sociólogos, nas condições favorabilíssimas em que se achavam os mesmos norteamericanos - estabelecidos num território fértil, com um clima estimulante, e ao mesmo tempo saudável e propício, possuindo no próprio solo o ferro e a hulha, elementos indispensáveis e bastantes para organizar uma indústria desenvolvidíssima e apurada como essa que atualmente se vê ali. ${ }^{23}$

A crítica dos sociólogos e dos políticos ao Brasil advinha da inexistência da indústria e da materialização do progresso econômico. No entanto, para o pensador, o progresso presente nos Estados Unidos não era explicado apenas pelo "espírito empreendedor" do norte-americano, mas também pelas condições favoráveis que existiam naquele país, como por exemplo, o solo, o clima, etc. Bomfim não fecha a análise "na propensão inata", mas identifica as singularidades de cada país e, consequentemente, das diferentes etnias/povos em alcançar os ideais propagados pelos europeus.

Como anteriormente colocado, ao analisar o progresso presente na América, antes da chegada dos europeus, Bomfim ratifica a potencialidade de alcance do progresso, nas diferentes civilizações, de acordo com sua vontade/necessidade. Nessa perspectiva de pensamento, o que era considerado progresso para um povo, em um momento histórico específico, poderia não ser para outro:

que os índios e africanos são "incapazes" de atingir a um grau de perfeição moral e social comparável aos dos povos cultos atuais. Que é que prova serem eles assim incapazes e inferiores?... "O fato de se manterem até agora selvagens ou bárbaros". É esta a única prova positiva apresentada ... Mal se compreendem como esses ho-

23 BOMFIM, Op. cit., págs. 252-253. 
mens confundem assim, lastimosamente, as "alternativas histórica dos povos" com "inferioridade definitiva das raças". Demais, será verdade que os indígenas americanos não tenham dado nenhuma prova de que sejam capazes de atingir a civilização superior? Não; há na história a demonstração categórica da perfectibilidade social destes povos. ${ }^{24}$

Bomfim trouxe para o debate a questão da diferença entre "alternativas históricas" e "inferioridade definitiva" e, neste ponto, identifica-se um elemento importante para discussão. No primeiro enunciado tem-se a ideia da possibilidade de progresso/transformação social para todos os povos, de acordo com a vontade/necessidade destes. Já no segundo não existia esta perspectiva, pois a ideia de possibilidade de progresso se funda na de inferioridade inata dos povos. Essa perspectiva era aceita pela maioria dos contemporâneos do autor.

Interessante ressaltar que, também nessa discussão, Bomfim utiliza-se de alguns termos correntes em seu tempo, mesmo divergindo na essência com esses discursos. $\bigcirc$ termo "selvagem" carrega visões específicas sobre o grau de civilização e de progresso de uma sociedade, e incita à construção de imagens da diferença entre os povos. Assim, mesmo que Bomfim rompesse com o discurso da "inferioridade", também pactuava com alguns dos termos/idéias correntes.

Para romper com a visão de progresso pautada no parâmetro europeu, presente em seu tempo, Bomfim realizou interessante reflexão sobre a superioridade de uma raça e seu progresso:

Destarte a superioridade da raça, que deverá ser definitiva para que possa prevalecer, deixa de ser definitiva. Estes, que são superiores hoje, eram inferiores há dois séculos; a superioridade de então pertencia aos espanhóis e portugueses. Outra extravagância: os anglo-saxões são superiores porque conseguiram criar nos Estados Unidos uma nação prodigiosamente próspera; mas no Canadá, serão inferiores, pois que a colônia, ali, se arrasta mesquinha e reduzida, dez vezes menos populosa e cem vezes menos rica que os Estados Unidos. Os ingleses são superiores, porque a Inglaterra mantém os celtas da Irlanda subjugados e impotentes; o celta é superior porque expulsou o inglês da França. ${ }^{25}$

Quanto ao progresso, Bomfim argumenta que ele foi, ao longo do tempo, tomando diferentes formas entre as nações ditas civilizadas. Uma nação muito avançada em um tempo, logo é superada por outra e assim sucessivamente; muitas vezes a visão sobre o progresso foi determinada pela riqueza econômica da nação. Ingleses, franceses, portugueses lutaram pela supremacia, superando-se mutuamente, ininterruptamente. Muito desse progresso se fez pelo suor/sangue do escravo. Atos de exploração de um ser humano sobre outro eram cometidos em nome do progresso, culminando

24 Ibidem, pág. 254.

25 lbidem, pág. 250. 
por legitimar a violência. Tais experiências, no olhar de Bomfim, foram entendidas como retrocesso, igualando o homem ao ser mais baixo na escala natural:

Extraordinários, estes moralistas e sociólogos que esperam melhorar, aperfeiçoar o homem, fazendo-o voltar justamente à primitiva condição animal!... Se o homem conserva ainda estes instintos, que trouxe do seio das florestas, o empenho deve ser para eliminá-los. É pelo esforço na luta, não há duvida, que o homem progride; mas a luta é contra a natureza, e, nesta luta, só a união dos esforços garante a vitória. $\bigcirc$ papel do homem na civilização, é conquistar esta mesma natureza, impor-se a ela, e dar à evolução a marcha que lhe parecer melhor para a conquista de um ideal; e não entregar-se à brutalidade da fera, para a qual o futuro não tem significação e não o entregar-se a essas brutalidades sob a alegação de que elas são naturais nos outros animais. ${ }^{26}$

Naquele contexto, o progresso econômico estava ligado à questão da raça. Ao negro, no olhar europeu, era impossível alcançá-lo, isso tendo em vista sua própria imagem. Bomfim, ao chamar atenção para os diferentes estágios em que se encontravam os povos, busca também ressaltar as características próprias de cada povo/etnia, e entende que não haviam alcançado o progresso econômico dos europeus, mas conseguiram o progresso social.

\section{Conclusão}

A argumentação de Bomfim foi elaborada a partir do estudo da história do Brasil no contexto latinoamericano, intentando fixar marcos representativos para a escrita da história do país, recusando a simples narração de fatos oficiais, heróis e datas. Bomfim destoou do pensamento intelectual de seu tempo ao afirmar que as relações sociais estabelecidas entre brancos, negros e índios no Brasil, eram desiguais. Para o pensador, seria impossível analisar de forma homogênea povos com diferentes condições de cultura e de educação. Assim, rompeu com a discussão da superioridade de um povo sobre o outro, e trilhou outros caminhos de investigação. Neste movimento formulou inovadoras concepções analíticas sobre o Brasil e a América Latina, buscando romper com o estigma da inferioridade muito presente nos discursos em voga, formulando outros parâmetros de interpretação. ${ }^{27}$

26 Ibidem, págs.255-256.

27 Agradeço a Aldo Duran Gil (professor da UFU) pelas sugestões e críticas do texto. 


\section{Bibliografía}

AGUIAR, Ronaldo Conde. "Manoel Bomfim: um intérprete dissonante dos Males da America Latina" in CRUZ, José Vieira da; JÚNIOR, Antonio Bittencourt (org.). Manoel Bomfim e a América Latina: a dialética entre o passado e o presente. Aracajú: Editora Diário Oficial, 2010.

CÂNDIDO, Antonio. "Radicalismos" in Revista do Instituto de Estudos Avançados. São Paulo, v. 4 (8) janeiro/abril 1990.

LINS, Ivan. História do positivismo no Brasil. São Paulo: Companhia Editorial Nacional, 1967.

PRADO, Maria Lígia. A formação das nações latino-americanas. São Paulo: Atual, 1994.

PRADO JÚNIOR, Caio. Formação do Brasil Contemporâneo: Colônia. São Paulo: Brasiliense, 1999.

ROMERO, Silvio. Provocações e Debates. Contribuições para o Estudo do Brazil Social. Porto/Rio de Janeiro: Imprensa Moderna, 1908.

SANTOS, Regma Maria dos. Memórias de um plumitivo: Impressões cotidianas e histórias nas crônicas de Lycidio Paes. Uberlândia: Asppectus, 2005.

SILVA, José Maria de Oliveira. "Manoel Bomfim e a obra América Latina: a dialética entre passado e presente" in Manoel Bomfim e a América Latina: a dialética entre o passado e o presente. CRUZ, José Vieira da \& JÚNIOR, Antonio Bittencourt (org.). Aracajú: Editora Diário Oficial, 2010.

SILVEIRA, Cristiane da. (Re)leituras de Manoel Bonfim: a escrita da história do Brasil e o ser negro na passagem do século XIX para o XX. Programa de Pós-Graduação em História Social da Pontifícia Universidade Católica de São Paulo (PUC/SP). Tese de doutorado, 2011 .

SUSSENKIND, Flora \& VENTURA, Roberto. História e dependência: cultura e sociedade em Manuel Bomfim. São Paulo: Moderna, 1984.

VENTURA, Roberto. "Manoel Bomfim, um rebelde atual" in Revista Brasileira de Literatura n. 34. São Paulo, maio de 2000.

2003. 